\title{
PROJETO DE EXTENSÃO CENTRO DE CUIDADOS DE ENFERMAGEM
}

\author{
Franciele Soares ${ }^{1}$, Taniclaer Stahlhoefer ${ }^{1}$, Eliane Cristina Sanches Maziero ${ }^{2}$, Marineli Joaquim Meier ${ }^{3}$, Simone Aparecida
} Peruzzo ${ }^{4}$, Samanta Andrine Marschall Taube ${ }^{5}$

\begin{abstract}
RESUMO: O Projeto de Extensão “Centro de cuidados de Enfermagem: integrando o ensino, a pesquisa e a extensão” do Departamento de Enfermagem da Universidade Federal do Paraná permite ao acadêmico/bolsista unir o ensino e a prática profissional do enfermeiro. O objetivo deste relato é descrever as atividades desenvolvidas pelo Centro de Cuidados entre junho e dezembro de 2007. As atividades se concentraram em um colégio da rede pública, onde foi instalado um consultório para atendimentos de enfermagem. Foram realizadas 313 consultas frente a queixas de cefaleia, tontura, contusão, malestar relacionado à hipertensão, cólica menstrual, náusea e pequenos cortes e/ou lesões, o que desencadeou cerca de 500 intervenções. Os atendimentos permitiram a prática dos conhecimentos adquiridos em sala de aula, além de oportunizar o trabalho em equipe, parcerias e a pesquisa. A experiência oportunizou aos acadêmicos vivenciar o processo de trabalho do enfermeiro e a aproximação com a comunidade.
\end{abstract}

PALAVRAS-CHAVE: Serviços de enfermagem escolar; Cuidados de enfermagem; Educação em saúde.

\section{NURSING CARE CENTER EXTENSION PROJECT}

\begin{abstract}
The Department of Nursing Extension Project "Nursing Care Center: integrating teaching, research and extension" of the Federal University of Parana allows the academic/ scholarship student to connect professional nursing practice and education. The purpose of this report is to describe the activities of the Care Center between June and December 2007. The activities focused on a public school, which installed an office for nursing care. 313 consultations were performed, in order to attend complaints of headache, dizziness, bruising, discomfort related to hypertension, menstrual cramps, nausea and minor cuts and /or injuries, which led to near 500 interventions. The consultations allowed the practice of knowledge acquired in the classroom, and arouse opportunities for teamwork, partnerships and research. The experiences offered the students to experience the process of nursing work and an approach with the community.
\end{abstract}

KEYWORDS: School nursing services; Nursing care; Health Education.

\section{PROYECTO DE EXTENSIÓN CENTRO DE CUIDADOS DE ENFERMERÍA}

RESUMEN: El Proyecto de Extensión “Centro de cuidados de Enfermería: integrando la enseñanza, la investigación y la extensión” del Departamento de Enfermería de la Universidad Federal del Paraná permite al académico/becario unir la enseñanza y la práctica profesional del enfermero. El objetivo de este relato es describir las actividades desarrolladas por el Centro de Cuidados entre Junio y Diciembre de 2007. Las actividades se concentraron en un colegio de la red pública, donde fue instalado un consultorio para atendimientos de enfermería. Fueron realizadas 313 consultas frente a quejas de cefalea, tontura, contusión, mal-estar relacionado a hipertensión, cólica menstrual, náusea y pequeños cortes y/o lesiones lo que desencadenó cerca de 500 intervenciones. Los atendimientos permitieron la práctica de los conocimientos adquiridos en sala de aula, además de dar oportunidad al trabajo en equipo, sociedad y la investigación. La experiencia dio oportunidad a los académicos vivir el proceso de trabajo del enfermero y la aproximación con la comunidad.

PALABRAS CLAVE: Servicios de enfermería escolar; Cuidados de enfermería; Educación en salud.

\footnotetext{
${ }^{1}$ Acadêmica do Curso de Graduação em Enfermagem da Universidade Federal do Paraná-UFPR. Bolsista do Projeto de Extensão Centro de Cuidados de Enfermagem-CCEnf.

${ }^{2}$ Enfermeira. Professora Substituta do Departamento de Enfermagem do DENF-UFPR. Membro do Grupo de Estudos Multiprofissional em Saúde do Adulto-GEMSA do DENF-UFPR.

${ }^{3}$ Enfermeira. Doutora em Enfermagem. Professor Adjunto do DENF-UFPR. Vice-Coordenadora do CCEnf.

${ }^{4}$ Enfermeira. Mestre em Enfermagem. Enfermeira Colaboradora do CCEnf.

${ }^{5}$ Enfermeira. Mestre em Enfermagem. Professora Assistente do DENF-UFPR. Coordenadora do CCEnf.
}

Autor correspondente:

Samanta Andrine Marschall Taube

Universidade Federal do Paraná

Rua Padre Camargo, 120 - 80060-240 - Curitiba-PR, Brasil

Recebido: 20/08/09

E-mail: samitaube@gmail.com

Aprovado: 24/02/10 


\section{INTRODUÇÃO}

O Centro de Cuidados de Enfermagem (CCEnf) é um Projeto de Extensão vinculado ao Departamento de Enfermagem da Universidade Federal do Paraná (UFPR). Foi criado em 2001 e tem como objetivos integrar a academia à comunidade, por meio de ações educativas e assistenciais, para a melhoria da qualidade de vida da população. Ao mesmo tempo, proporciona aos bolsistas a vivência do processo de trabalho do enfermeiro, ao oportunizar um espaço de aprendizagem das ações de cuidado. Nesse sentido, o CCEnf configura-se como uma atividade de cunho educativo, cultural e científico que articula o ensino e a pesquisa de forma indissociável ${ }^{(1)}$ e, concomitantemente, viabiliza uma relação entre a Universidade e a sociedade.

Desde sua criação o CCEnf consolida parcerias com instituições de saúde, ensino e comunicação, dentre as quais se destaca a que fez com um colégio estadual da rede pública da capital paranaense. Neste, são desenvolvidas atividades educativas como oficinas, palestras e educação em saúde individual e ações assistenciais, efetivadas por meio da Consulta de Enfermagem.

$\mathrm{Na}$ experiência, destacam-se as ações de educação para a saúde sexual e reprodutiva, as de prevenção de doenças sexualmente transmissíveis (DST) e gravidez na adolescência, prevenção ao uso de álcool, tabaco e outras drogas, além da Educação em Saúde direcionada para os profissionais da escola, no que se refere aos cuidados com a saúde para a manutenção de sua qualidade de vida. Sendo assim, acredita-se que o trabalho desenvolvido pelos acadêmicos de enfermagem (extensionistas bolsistas e voluntários) vai ao encontro dos objetivos do Programa Saúde na Escola, do Ministério da Saúde e da Educação, que tem por objetivo ampliar ações específicas de saúde por meio da prevenção e promoção da saúde dos estudantes da Rede Pública de Ensino ${ }^{(2)}$.

Nesse sentido, ressalta-se a importância da presença de profissionais de saúde no ambiente escolar, os quais busquem auxiliar os adolescentes por meio de ações de educação em saúde que enfoquem a realidade desta população. Sabe-se que professores/ escolas desempenham papel central na construção da rede de relações, bem como da identidade do adolescente. No entanto, no que concerne à educação sexual, é importante considerar o fato de que muitos professores sentem-se despreparados em lidar com aspectos da orientação junto a seus alunos ${ }^{(3-4)}$. Além disso, muitas vezes, a figura dos pais mostra-se insuficiente para suprir tais demandas, pois esses revelam dificuldades para trabalhar questões referentes à sexualidade, violência e uso de drogas junto a seus filhos. Como resultado, eles transferem o papel educativo que lhes cabe para terceiros, principalmente delegando à escola quase que inteiramente o seu papel de educador ${ }^{(3,5-6)}$.

Sendo assim, percebe-se a relevância de compartilhar a participação de um grupo de acadêmicas de Enfermagem em um Projeto de Extensão. Este permite que os extensionistas apliquem na prática os conteúdos de disciplinas do curso de graduação e aprimorem habilidades adquiridas no decorrer do curso como, por exemplo, a comunicação, a destreza manual, o trabalho em equipe, a organização e planejamento, o raciocínio clínico e a capacidade de tomada de decisões. Desta forma, o Projeto contribui ao processo de ensinoaprendizagem no aprofundamento de conhecimentos teóricos e práticos ${ }^{(7)}$.

Assim, este artigo trata de um relato de experiência que objetiva descrever as atividades desenvolvidas pelo grupo de bolsistas integrantes do projeto CCEnf, no período entre junho e dezembro de 2007, em um colégio estadual da capital paranaense.

\section{DESENVOLVIMENTO}

Desde a sua criação em 2001, o CCEnf coloca em prática os seus objetivos e direciona as ações de acordo com a demanda do público-alvo e das perspectivas de seus parceiros. Para seu desenvolvimento, conta com uma equipe composta por um coordenador, professores colaboradores e acadêmicos do curso de graduação de Enfermagem da UFPR. Para o ano de 2007, as atividades do projeto foram retomadas no mês de junho, após a seleção de cinco novas bolsistas, acadêmicas do segundo ao oitavo períodos do curso.

A primeira reunião do ano de 2007objetivou apresentar às alunas a prioridade da retomada das atividades junto ao colégio, cujo público-alvo é de 4 mil alunos adolescentes e jovens matriculados em três turnos. Neste encontro foram acordadas as atividades das bolsistas, sendo a primeira delas a realização de um levantamento bibliográfico e estudo dos temas comumente abordados entre os adolescentes e jovens, como DST/aids, alcoolismo, drogadição, métodos contraceptivos, distúrbios alimentares e sexualidade.

Cabe ressaltar que a adolescência é conceituada como o período entre 12 e 18 anos de idade ${ }^{(8)}$, no qual se registram dúvidas, principalmente a respeito do 
desenvolvimento sexual e social, por constituir-se uma fase de mudanças significativas da imagem (corpo) e papel (atitudes). É uma fase em que o indivíduo reformula conceitos pessoais e que é marcada pela aquisição da identidade pessoal e da capacidade de reprodução, o que o faz transpor a autoimagem infantil e a projetar-se no futuro da vida adulta ${ }^{(9-10)}$.

Para a complementação dos estudos das bolsistas a respeito do tema "adolescência", outra atividade realizada foi a participação em seminários e eventos cuja temática foi a comunicação com o adolescente e a educação em saúde individual e coletiva.

Após esta etapa, as ações focaram na elaboração de protocolos que fundamentassem o desenvolvimento da Consulta de Enfermagem, compreendida como uma atividade privativa do enfermeiro cujos objetivos estão em identificar problemas de saúde/doenças da população, e prescrever e implementar medidas que colaborem com a promoção, proteção, recuperação e reabilitação da saúde ${ }^{(11)}$.

Os protocolos permitiram o direcionamento, padronização e qualidade dos atendimentos aos adolescentes no colégio, o qual cedeu uma sala para a efetivação da consulta de enfermagem. Nesta sala foram alocados equipamentos e insumos necessários ao acolhimento e atendimento. A Consulta de Enfermagem é de responsabilidade da Coordenadora do Projeto de Extensão. Vencida esta etapa, os bolsistas iniciaram a divulgação do projeto nas salas de aula do colégio, no intuito de se apresentarem aos alunos, professores e pedagogos e, ao mesmo tempo, divulgar o trabalho a ser oferecido pelo CCEnf.

As consultas iniciaram-se no mês de agosto de 2007, ocorrendo diariamente, no período da tarde, conforme escala de atividades das bolsistas. Esclarecese que estas frequentam o curso de graduação pela manhã e participam do projeto no contra turno, sendo assim, o consultório permanece com duas bolsistas por tarde. Reconhece-se que esta disposição permite a existência de uma lacuna no atendimento à demanda existente na instituição, e que parte do público-alvo não é contemplado pelas ações do projeto, porém esforços vêm sendo feitos para ampliar a atuação.

No mês de agosto de 2007 foram realizadas 54 consultas de enfermagem, a partir das quais mais de duzentas intervenções foram registradas, as quais variaram de educação em saúde e esclarecimentos, até atendimento a traumas e emergências. Enfatizase que em cada consulta de enfermagem é possível intervir mais de uma vez em função da existência de mais de um "problema” de enfermagem diagnosticado, fato que justifica um número maior de intervenções do que de consultas realizadas.

Quanto ao perfil dos usuários atendidos em agosto, ele foi em sua maioria de adolescentes na faixa etária de 16 anos, além de funcionários (professores, serviços gerais e administrativos) de diferentes idades. Entre as principais queixas observou-se cefaléia, tontura, contusão, mal-estar relacionado à hipertensão, cólica menstrual, náuseas e pequenos cortes e/ou lesões.

As intervenções de enfermagem realizadas a partir da consulta foram: oferecimento de chá para aliviar sintomas; encaminhamentos para os pais, coordenação ou Serviço de Atendimento Médico de Urgência; aplicação de medidas de conforto (repouso, aplicação de calor e frio); aferição de pressão arterial; curativos e educação de saúde individual. Destacam-se as ações direcionadas às queixas, sendo que os temas que foram tratados nas ações educativas individuais foram relacionados a alimentação adequada, sexualidade e gravidez na adolescência.

Percebe-se que, diariamente, conteúdos teóricos do curso de graduação de Enfermagem foram aplicados, na prática, pelas acadêmicas, o que permitiu às alunas aperfeiçoar suas habilidades e conhecimentos, pois cada questão elencada durante a consulta de enfermagem as reportava às disciplinas e reforçava a necessidade de pesquisa e atualização constantes.

A educação em saúde permite ao indivíduo reconhecer, compreender e intervir em seu próprio processo saúde-doença, e a atividade fez com que as bolsistas exercessem o papel de educadoras. Este trabalho é inerente ao profissional de Enfermagem e se configura como uma das dimensões do processo de trabalho do enfermeiro a serem contempladas na

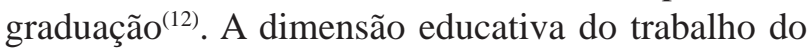
enfermeiro exige competências e habilidades que devem ser desenvolvidas durante a formação, pois ações de educação em saúde à comunidade mostramse necessárias e podem ser realizadas em diferentes campos de atuação profissional ${ }^{(13)}$.

No mês de setembro foram realizadas 160 consultas, correspondente ao triplo do computado no primeiro mês, o que demonstrou reconhecimento da comunidade quanto ao trabalho do CCEnf. Este fato estimulou as bolsistas a elaborar e participar, juntamente com os acadêmicos de Enfermagem da disciplina de "Prática de Ensino", do Setor de Educação da UFPR, de oficinas de capacitação disponibilizadas 
a alunos e professores do colégio. Estas atividades abordaram temas relacionados a primeiros socorros frente a hemorragia, queimaduras, desmaio/síncope e parada cárdiorrespiratória, além de outras situações referentes à saúde, comumente vivenciadas na instituição. Além disso, a equipe do CCEnf participou de eventos produzidos em parceria com alguns adolescentes do próprio Colégio, intitulados “Alunos protagonistas”, os quais multiplicam informações entre seus pares, com enfoque no tema sexualidade e planejamento familiar.

Nos meses subsequentes, outubro e novembro de 2007, registrou-se decréscimo no número das consultas e intervenções realizadas (99 Consultas de Enfermagem nos dois meses) devido à paralisação no colégio, desencadeada por alunos, pais e professores. Tal acontecimento foi percebido como um momento de aprendizagem ao Projeto, uma vez que fatores externos são imprevisíveis e podem interferir no planejamento das ações de extensão e do trabalho profissional. Ao final do período letivo de 2007, o CCEnf havia totalizado 313 consultas e cerca de 500 intervenções de enfermagem, revelando a demanda e a confiança da instituição parceira no trabalho.

Para as integrantes do projeto, a complexidade e demanda do Consultório de Enfermagem expuseram a necessidade constante de atualização, aprendizado e exercício com os instrumentos básicos de Enfermagem, tais como a destreza manual, a organização, o conhecimento científico, o trabalho em equipe e a criatividade. No dia-a-dia, as bolsistas utilizam estes instrumentos para a prática do cuidar, pois se deparam com situações em que os recursos foram insuficientes, remetendo ao uso de uma das habilidades básicas da Enfermagem: a criatividade. Essa é uma ferramenta necessária ao processo de trabalho do enfermeiro, pois conduz à busca por soluções de problemas de uma maneira diferente do habitual ${ }^{(14)}$.

\section{CONSIDERAÇÕES FINAIS}

Os resultados mostram a pertinência do projeto por possibilitar ao extensionista vivenciar o processo de trabalho do enfermeiro em um novo ambiente: o espaço escolar. A parceria com uma escola que recebe um público adolescente proporcionou às bolsistas uma experiência singular, repleta de desafios, entre eles trabalhar com temas como sexualidade e drogadição.

Ser extensionista fez aprimorar habilidades fundamentais à prática profissional do futuro enfermeiro, tais como o raciocínio clínico e a tomada de decisão, o que envolveu a escolha do tipo de exame físico, enfoque, seleção e construção do instrumento de coleta de dados e definição do diagnóstico e intervenção. Destaca-se o trabalho em equipe no desenvolvimento de escalas para distribuição das atividades entre as bolsistas, presença em reuniões do projeto, realização de trabalhos escritos, atividades de planejamento e execução.

A experiência aqui relatada demonstra que o CCEnf torna-se, a cada ano, um espaço para que os acadêmicos de Enfermagem vivenciem o processo de trabalho do enfermeiro em um ambiente diferente dos habituais, além de terem a oportunidade de trabalhar e se aproximar da comunidade.

\section{REFERÊNCIAS}

1. Penna LHG, Correia LM, Silveira ACF, Salgado APA. Projeto de extensão universitária: a enfermagem obstétrica no atendimento pré-natal de baixo risco. Rev Enferm UERJ. 2006;14(2):253-9.

2. Ministério da Saúde (BR). Departamento de Atenção Básica. Programa Saúde na Escola. [Internet]. 2004 [acesso em 15 jul 2009] Disponível: http://dtr2004.saude. gov.br/dab/programa_saude_na_escola.php

3. Silva IO, Glória VHS, Rocha WF. Educação sexual e gravidez de adolescentes: significados construídos por docentes do curso de formação de professores em uma escola pública do Rio de Janeiro, Brasil. REEC. 2009;8(1):216-31.

4. Bretãs JRS, Silva CV. Orientação sexual para adolescentes: relato de experiência. Acta Paul Enferm. 2005;18(3):326-33.

5. Almeida IS, Rêgo BM, Rodrigues D, Simões SMF. O adolescer... um vir a ser. Adolesc Saúde. 2007;4(3):24-9.

6. Njaine K, Minayo MCS. Violence in schools: identifying clues for prevention, Interface - Comunic Saúde Educ. 2003;7(13):119-34.

7. Assis F, Borsatto AZ, Silva PDD, Rocha PR, Lopes GT, Peres PL. Programa de monitoria acadêmica: percepções de monitores e orientadores. Rev Enferm UERJ. 2006;14(3):391-7.

8. Brasil. Lei n. 8.069, de 13 de julho de 1990. Dispõe sobre o estatuto da criança e do adolescente e dá outras providências. Diário Oficial da União. [Internet]. 1990 
[acesso em 15 jul 2009]. Disponível: http://www.planalto. gov.br/ccivil/LEIS/L8069.htm.

9. Neiva KMC, Abreu M, Ribas TP. Adolescência: facilitando a aceitação do novo esquema corporal e das novas formas de pensamento. Revista Psicol. 2004;5(2):56-64.

10. Girondi JBR, Nothaft SCS, Mallmann FMB. A metodologia problematizadora utilizada pelo enfermeiro na educação sexual de adolescentes. Cogitare Enferm. 2006;2(11):161-5.

11. Brasil. Lei n. 7.498, de 25 de junho de 1986. Dispõe sobre a regulamentação do exercício da enfermagem e dá outras providências. Diário Oficial da República Federativa do Brasil, Brasília, 26 jun. 1986. Seção 1:1. Brasil. Constituição da República Federativa do Brasil. Brasília: Senado;1988.

12. Taube SAM. Processo de trabalho da enfermeira na central de material e esterilização: uma perspectiva tecnológica aos instrumentos [dissertação]. Curitiba (PR): Universidade Federal do Paraná; 2006.

13. Fernandes CNS. Refletindo sobre o aprendizado do papel de educador no processo de formação do enfermeiro. Rev Latino-Am Enfermagem. 2004;12(4):691-3.

14. Cianciarullo TI. Instrumentos básicos para o cuidar: um desafio para a qualidade de assistência. São Paulo: Atheneu; 2003. 